\title{
PROTECCIÓN CONSTITUCIONAL DEL DERECHO A LA VIDA PRENATAL FRENTE A LA OBLIGACIÓN DE RESPETAR LOS DERECHOS DE LA MUJER: SU POSIBLE COMPATIBILIDAD
}

\section{Constitutional protection of the right to prenatal life and the obligation of respect to women's rights: Their possible compatibility.}

\author{
Ana LUNA SERRANO' \\ Bryan SÁNCHEZ AGUSTIIN ${ }^{2}$
}

\section{Sumario:}

I. Introducción. II. Impacto de la despenalización del aborto en el Distrito Federal. III. Estándares internacionales sobre la protección del derecho a la vida prenatal. IV. Conclusiones. V. Bibliografía.

Resumen: En el presente trabajo se analiza el impacto que siguen teniendo la despenalización del aborto y la reforma a la Ley Sanitaria, que dieron como resultado el acceso de manera segura a la interrupción legal del embarazo en el Distrito Federal en 2007. Particularmente se hace referencia a las reformas que han introducido en las constituciones locales la protección de la vida desde el momento de la concepción y en algunas desde el momento de la fecundación. A partir de lo anterior se identifican los estándares internacionales aplicables a la protección del derecho a la vida prenatal, los cuales permiten sostener el que no necesariamente son mutuamente excluyentes la protección de la vida prenatal con la protección de los derechos de la mujer embarazada.

Palabras clave: Derecho a la Vida; Derecho Internacional de los Derechos Humanos; Aborto.

Abstract: This article analyzes the impact that the decriminalization of abortion and the amendment to the Sanitary Law, which resulted in the legal and safe access to abortion in Mexico City on 2007. Particularly, we will refer to the amendments that have incorporated the protection of life from the moment of conception. Based in the aloved mentionet, we identify the International Human Rights Law standards related to this matter, which allow us to sustain that the protection of prenatal life and the rights of the pregnant woman are not necessarily mutually exclusive.

Keywords: Right to life. International Human Rights Law. Abortion.

\footnotetext{
1 Profesora de Tiempo Completo de la Universidad Autónoma de Baja California, Maestra en Derecho Internacional por el Tecnológico de Monterrey, estudiante del Doctorado Interinstitucional en Derecho por la Universidad Autónoma de Aguascalientes, ana.luna.serrano@uabc.edu.mx.

2 Estudiante de la Licenciatura en Derecho de la Universidad Autónoma de Baja California, bryan.sanchez@ uabc.edu.mx. 


\section{INTRODUCCIÓN}

En el año 2007 la asamblea legislativa del Distrito Federal aprobó la propuesta de reforma a los artículos $144^{\circ}, 145^{\circ}, 146^{\circ}$ y $147^{\circ}$ del código penal del Distrito Federal, así como la adición de los artículos $16^{\circ}$ bis $6,16^{\circ}$ bis 7 y $16^{\circ}$ bis 8, de la Ley de Salud para el Distrito Federal. Con lo anterior se despenalizaba y garantizaba el acceso al aborto durante las primeras 12 semanas de gestación.

Como consecuencia de lo acontecido en el Distrito Federal y con el fin de evitar una eventual despenalización del aborto, dentro de las legislaturas de diversos estados de la República comenzaron a realizarse reformas a las constituciones locales, incorporando a dichos textos constitucionales la tutela del derecho a la vida desde el momento de la concepción. Específicamente, se modificó el texto constitucional de 17 entidades federativas a partir del año 2007, dando como resultado que actualmente en $18^{3}$ de las 32 entidades federativas, sea tutelado constitucionalmente el derecho a la vida desde el momento de la concepción.

A nueve años de la despenalización del aborto en el Distrito Federal, la temática mantiene relevancia debido a la persistencia por parte de las entidades federativas de darle carácter constitucional a la protección de la vida prenatal. La última reforma de este tipo se aprobó el 22 de enero de 2016 a la Constitución de Veracruz. Cabe mencionar también que en diversos estados se han presentado iniciativas de la misma naturaleza, pero que no han sido aprobadas debido al extenso debate que se ha generado a partir de las mismas.

Dentro de este trabajo se pretende analizar, primeramente, la resolución de la Suprema Corte de Justicia de la Nación (en adelante, SCJN) a la acción de inconstitucionalidad 146/2007 y su acumulada 147/2007 relativas a la despenalización del aborto en el Distrito Federal y, posteriormente, los casos en los que la constitucionalidad de las reformas a las constituciones locales para incluir una protección del derecho a la vida prenatal fue analizada por la SCJN. Finalmente, se hará referencia a los estándares internacionales referentes a la protección del derecho a la vida prenatal, concluyendo con las implicaciones que tiene la constitucionalización de la protección de este derecho en las distintas entidades federativas en relación con dichos estándares.

\section{IMPACTO DE LA DESPENALIZACIÓN DEL ABORTO EN EL DISTRITO FEDERAL}

1. ACCIÓN DE INCONSTITUCIONALIDAD $146 / 2007$ Y $\quad$ SU ACUMULADA $147 / 2007$ CORRESPONDIENTE AL DISTRITO FEDERAL

Como resultado de la aprobación de la ya referida reforma a los artículos $144^{\circ}, 145^{\circ}, 146^{\circ}$ y $147^{\circ}$ del Código Penal del Distrito Federal, así como la adición a los artículos $16^{\circ}$ bis $6,16^{\circ}$ bis 7 y $16^{\circ}$ bis 8 de la Ley de Salud para el Distrito Federal a través de la cual se despenaliza y garantiza el acceso al aborto durante las primeras 12 semanas de gestación, la Comisión Nacional de los Derechos Humanos (en adelante, $\mathrm{CNDH}$ ) así como la Procuraduría General de la República (en adelante, PGR), presentaron cada una respectivamente una acción de inconstitucionalidad ante la SCJN, asentadas en los expedientes 146/2007 así como su acumulada 147/2007. Dichas demandas coincidían en el reclamo de la inconstitucionalidad de la reforma hecha a los artículos $144^{\circ}, 145^{\circ}, 146^{\circ}$ y $147^{\circ}$ del Código Penal para el Distrito Federal

3 Baja California, Chiapas, Chihuahua, Colima, Durango, Guanajuato, Jalisco, Morelos, Nayarit, Oaxaca, Puebla, Querétaro, Quintana Roo, San Luis Potosí, Sonora, Tamaulipas, Veracruz, Yucatán. Véase Anexo I. 
así como de la adición al tercer párrafo el artículo $16^{\circ}$ Bis 8 en el último párrafo de la Ley de Salud para el Distrito Federal, las cuales habían sido previamente realizadas mediante decreto publicado en la Gaceta Oficial del Distrito Federal el 26 de abril de 2007 y promulgada por el Jefe de Gobierno del Distrito Federal.

Los preceptos constitucionales que se consideraban eran violados con la introducción de dichas disposiciones normativas a la constitución son los artículos $1^{\circ}, 4^{\circ}, 6^{\circ}, 14^{\circ}, 16^{\circ}, 22^{\circ}, 24^{\circ}$, $122^{\circ}$, apartado C, Base Primera, fracción V, primer párrafo, incisos h) e i), $123^{\circ}$, apartado A, fracciones V y XV, y Apartado B, fracción XI, inciso c), y $133^{\circ}$ de la Constitución Política de los Estados Unidos Mexicanos, ${ }^{4}$ además de lo anterior, el Procurador General de la República solicitó también la invalidez del artículo Tercero transitorio del Decreto reformado.

Entre los conceptos de invalidez presentados por la CNDH se encontraba la supuesta incompatibilidad con el derecho a la vida del producto de la concepción; el derecho a la vida; el derecho a la protección del proceso de gestación; los derechos de igualdad, procreación y paternidad; el derecho a la igualdad y no discriminación; el derecho a la igualdad y no discriminación por razón de edad; la inexacta aplicación de la Ley Penal; la invasión de competencias; el derecho de objeción de conciencia y el derecho a la salud en su dimensión social y principio de legalidad.

Por su parte la PGR colocó entre sus conceptos de invalidez la supuesta incompatibilidad con el derecho de procreación, el cual incluye la elección del número de hijos así como el espaciamiento entre ellos; la no satisfacción del principio supremo de certeza jurídica en materia penal; la supuesta violación de las garantías de no discriminación y de igualdad que dicha norma jurídica produciría. De igual manera, se consideraba que las medidas eran discriminatorias y que atentaban contra la dignidad humana al tener por objeto anular los derechos de los concebidos no nacidos menores a las 12 semanas de gestación.

Ante la gran expectativa que generó la resolución que habrían de tomar los ministros de la SCJN respecto al caso aquí analizado, que dio como resultado la realización de seis audiencias públicas y un proceso en el que diversos y variados sectores de la sociedad tuvieron una importante participación a través de diversos mecanismos, la Corte resolvió el 28 de agosto de 2008 que la acción de inconstitucionalidad 146/2007, así como su acumulada 147/2007, eran parcialmente procedentes e infundadas. Dichas acciones se sobreseyeron respecto de los artículos $148^{\circ}$ del Código Penal del Distrito Federal; $16^{\circ}$ Bis 7 de la Ley de Salud del Distrito Federal; y tercero transitorio del impugnado decreto de reforma a dicho precepto. Finalmente, se reconoció la validez de los artículos $144^{\circ}, 145^{\circ}, 146^{\circ}$ y $147^{\circ}$ del Código Penal para el Distrito Federal, así como de los artículos $16^{\circ}$ bis 6 , tercer párrafo, y $16^{\circ}$ bis 8 , último párrafo, de la Ley de Salud del Distrito Federal.

En la decisión del máximo tribunal del país no se estableció si se debe penalizar o no el aborto, ya que como lo mencionó el Ministro Guillermo I. Ortiz Mayagoitia, la SCJN no

\footnotetext{
$41^{\circ}$ relacionado a los Derechos Humanos; $4^{\circ}$ igualdad ante la ley; $6^{\circ}$ libre acceso a la información; $14^{\circ}$ efecto retroactivo de la ley; $16^{\circ}$ nadie podrá ser molestado en sus pertenencias;22 ${ }^{\circ}$ prohibición de la pena de muerte y otros tratos crueles e inhumanos; $24^{\circ}$ libertad de convicciones éticas, conciencia y religión;122 ${ }^{\circ}$ apartado C, Base Primera, fracción V primer párrafo incisos h, e i) disposiciones relacionadas a la integración del Distrito Federal; $123^{\circ}$, apartado A, fracciones V y XV, y Apartado B, fracción XI, inciso c) en base al derecho al trabajo así como disposiciones con perspectiva de género; $133^{\circ}$ de la Constitución Política de los Estados Unidos Mexicanos, conformación de la Ley Suprema de la Unión.
} 
tiene la facultad para tipificar conductas, ni fijar penas, dejando esto a discreción de las legislaturas de cada Entidad Federativa.

Con una votación de 8 votos a favor y 3 en contra del proyecto, se declaró la constitucionalidad de las reformas hechas por los miembros de la asamblea legislativa del Distrito Federal al Código Penal de dicho lugar, así como a la Ley de Salud del Distrito Federal.

2. REFORMAS A LAS CONSTITUCIONES DE BAJA CALIFORNiA Y SAN LUis POTOSí QUe TUTELAN EL DERECHO A LA VIDA DESDE EL MOMENTO DE LA CONCEPCIÓN Y ACCIONES DE INCONSTITUCIONALIDAD 11/2009 Y 62/2009

A raíz del impacto que generó la despenalización del aborto en el Distrito Federal, en diversas Entidades Federativas, las legislaturas locales optaron por realizar reformas a sus constituciones consistentes en la incorporación al texto constitucional de la tutela del derecho a la vida desde el momento de la concepción, y en algunos casos desde el momento de la fecundación. Estas reformas fueron implementadas como una forma de blindar el ordenamiento jurídico de dichos estados de una posible despenalización del aborto y pronto se convirtió en un práctica común entre las legislaturas.

Entre los estados de la República que incorporaron a su texto constitucional la tutela del derecho a la vida desde el momento de la concepción se encuentran Baja California y San Luis Potosí. Ambos casos serán estudiados en un apartado específico del presente trabajo debido a que la SCJN analizó la constitucionalidad de dichas reformas a partir de las acciones de inconstitucionalidad presentadas, respectivamente, por la Procuraduría de los Derechos Humanos de Baja California, y un grupo de legisladores de San Luis Potosí.

En el caso de Baja California, el H. Congreso del Estado reformó el artículo $7^{\circ}$ de la Constitución de dicha entidad federativa, ${ }^{5}$ incorporando como se mencionaba anteriormente la tutela al derecho a la vida desde el momento de la concepción, teniéndole desde entonces como persona nacida para todos los efectos legales que correspondan.

En el caso de San Luis Potosí se reformó el artículo $16^{\circ}$ de la constitución local, ${ }^{6}$ de manera que se tutelara el derecho a la vida desde el momento de la concepción, esto en razón de que según lo establecido dentro del mismo artículo, el derecho a la vida es fundamento de todos los derechos humanos.

\footnotetext{
5 Artículo $7^{\circ}$.- El Estado de Baja California acata plenamente y asegura a todos sus habitantes las garantías individuales y sociales consagradas en la Constitución Política de los Estados Unidos Mexicanos, así como los demás derechos que otorga esta Constitución; de igual manera esta norma fundamental tutela el derecho a la vida, al sustentar que desde el momento en que un individuo es concebido, entra bajo la protección de la ley y se le reputa como nacido para todos los efectos legales correspondientes, hasta su muerte natural o no inducida.

${ }^{6}$ Artículo $16^{\circ}$. El Estado de San Luis Potosí reconoce la vida humana como fundamento de todos los derechos de los seres humanos, por lo que la respeta y protege desde el momento de su inicio en la concepción. Queda prohibida la pena de muerte, la cual no podrá aplicarse en ningún caso.

No es punible la muerte dada al producto de la concepción, cuando sea consecuencia de una acción culposa de la mujer; el embarazo sea resultado de una violación o de una inseminación indebida; o de no provocarse el aborto la mujer corra peligro de muerte.
} 
a) Acción de Inconstitucionalidad 11/2009 correspondiente a la reforma constitucional al artículo $7^{\circ}$ del Estado de Baja California

En el caso de Baja California, ante la reforma hecha al artículo $7^{\circ}$ constitucional, párrafo primero, mediante el decreto 175 y publicado en el Periódico Oficial del Estado de Baja California el 26 de diciembre 2008, en ejercicio de su facultad, el entonces titular de la Procuraduría de los Derechos Humanos de Baja California ${ }^{7}$ promovió una acción de inconstitucionalidad en contra del recién reformado artículo séptimo, el cual, como se ha destacado anteriormente, protege la vida desde el momento de la concepción considerando al producto de la concepción como nacido para todos los efectos legales que correspondan. Dicho asunto quedó asentado en el expediente de número (11/2009) a cargo del Ministro Franco Salas.

El promovente de dicha acción de inconstitucionalidad, es decir el Procurador de los Derechos Humanos en Baja California, consideraba que dicho artículo debía ser declarado como inconstitucional debido a que violaba lo establecido en los artículos $1^{\circ}, 3^{\circ}, 4^{\circ}, 6^{\circ}, 14^{\circ}$, $16^{\circ}, 20^{\circ}, 22^{\circ}, 24^{\circ}$ y $133^{\circ}$ de la Constitución Política de los Estados Unidos Mexicanos. ${ }^{8}$ Se establecieron como conceptos de invalidez de dicha disposición el que violaba a la esfera de competencias de la federación por tratarse de legislación relativa a la fecundación in vitro. También se consideró que la norma que se buscaba impugnar condicionaba indebidamente el contenido de las normas secundarias, es decir, que dicha norma implicaría una protección absoluta en favor del no nacido. Asimismo, se alegaba que dicho precepto reconocía indebidamente el carácter de persona al concebido y no nacido; que dicha norma daba como resultado la restricción indebida de los derechos fundamentales de las mujeres; que el acto de autoridad legislativa que dio origen a dicha disposición se encontraba indebidamente fundado y motivado; y la presencia de violaciones que generaban la falta de certeza jurídica.

Ante lo anterior, el Ministro Franco González elaboró un proyecto en el que se consideraba debía declararse como inconstitucional la norma en cuestión, dicho proyecto tenía como ejes transversales la protección de la vida desde el momento de la concepción, los derechos fundamentales de las mujeres y la protección de la vida prenatal, así como los efectos del artículo $7^{\circ}$ de la Constitución de Baja California. El Ministro Franco consideró que si bien ni en los tratados en materia de Derechos Humanos ni en la Constitución Política de los Estados Unidos Mexicanos se contempla al producto de la gestación como individuo, esto no significaría el no reconocimiento del valor que tiene la vida humana prenatal. Además incluyó en su proyecto que la protección constitucional de la vida prenatal era inconstitucional, ya que vulneraba la dignidad así como la libertad reproductiva. De igual manera, el Ministro Franco consideró en su proyecto el que el artículo $7^{\circ}$ de la Constitución de Baja

\footnotetext{
7 Hoy denominada Comisión Estatal del Estado de Baja California.

8 Artículo $1^{\circ}$ de los derechos humanos; artículo $3^{\circ}$ derecho a la educación, la cual también es laica. Artículo $4^{\circ}$ igualdad ante la ley, elección del número de hijos así como su espaciamiento; artículo $6^{\circ}$ libre acceso a la información; artículo $14^{\circ}$ efecto retroactivo de la ley; artículo $16^{\circ}$ nadie podrá ser molestado en sus pertenencias; artículo $20^{\circ}$ principios rectores del juicio; artículo $22^{\circ}$ prohibición de la pena de muerte y otros tratos crueles e inhumanos; artículo $24^{\circ}$ libertad de convicciones éticas, conciencia y religión; artículo $133^{\circ}$ los tratados forman parte de la Ley Suprema de la Unión.
} 
California venía en detrimento de los derechos de la mujeres al reducirlas a un instrumento reproductivo.

Luigi Ferrajoli ${ }^{9}$ ha sostenido en este mismo sentido que cualquier decisión heterónoma externa a la voluntad de la mujer equivale a una lesión del segundo imperativo kantiano, ${ }^{10}$ según el cual ninguna persona puede ser utilizada como un instrumento, sino únicamente como un fin en sí misma. En el caso de la prohibición del aborto, equivalente a la obligación de convertirse en madre, se reduce a la mujer a un mero instrumento de procreación.

El proyecto del Ministro Franco consideraba que el brindar una protección a la vida era válido, sin embargo hacerlo desde el momento de la concepción no era una medida idónea ya que hacerlo traería un efecto negativo. No solo se estableció en el proyecto que debía de ser declarado como inconstitucional el extracto que brindaba una protección desde el momento de la concepción, sino también aquel que mencionaba la protección hasta su muerte natural o no inducida en razón a depender a la norma anteriormente mencionada.

A raíz de lo anterior, siete Ministros manifestaron su voto a favor de declarar como inconstitucional el artículo $7^{\circ}$ de la Constitución de Baja California. A pesar de que este número representa mayoría, de conformidad al artículo $72^{\circ}$ de la Ley Reglamentaria de las fracciones I Y II del artículo $105^{\circ}$ de la Constitución Política de los Estados Unidos Mexicanos,${ }^{11}$ debían de manifestarse 8 votos, por lo que se desestimó la acción y en consecuencia se ordenó archivar el asunto.

b) Acción de inconstitucionalidad 62/2009 correspondiente a la reforma hecha al artículo $16^{\circ}$ del Estado de San Luis Potosí

En el caso de San Luis Potosí, un grupo de 12 legisladores que formaban parte de la quincuagésima novena legislatura del congreso de dicha entidad federativa, promovieron una acción de inconstitucionalidad, a través de la cual se solicitaba la invalidez del artículo $16^{\circ} \mathrm{de}$ la constitución local, la cual había sido previamente reformada, a través del decreto 833, publicado en el periódico oficial de dicho Estado el 3 de septiembre de 2009, en el cual, además de tutelar el derecho a la vida desde el momento de la concepción, se establecía que la vida iniciaba en el momento de la concepción y que esta era fundamento de todos los Derechos Humanos.

Los legisladores que promovieron esta acción de inconstitucionalidad consideraban que el artículo 16 de la constitución local contravenía lo establecido en los artículos $1^{\circ}, 2^{\circ}, 3^{\circ}, 4^{\circ}$, $16^{\circ}, 24^{\circ}, 40^{\circ}, 41^{\circ}, 128^{\circ}, 130^{\circ}$ y $133^{\circ}$ de la Constitución Política de los Estados Unidos Mexicanos. ${ }^{12}$ Así mismo, al promover dicha acción establecieron entre sus conceptos de invalidez

9 FERRAJOLI, Luigi. "Derechos y garantías. La ley del más débil". Traducción de Perfecto Andrés Ibáñez y Andrea Greppi, 7a. ed., Madrid, Trotta, 2010, p. 85. También en La cuestión del embrión entre derecho y moral, jueces para la democracia. Información y debate, núm. 44, pp. 3-12, Madrid, 2002.

${ }^{10}$ KANT, I., La metafísica de las costumbres, trad. A. Cortina Orts, Tecnos, Madrid, 1989, pp. 166 y 335.

${ }^{11}$ Artículo $72^{\circ}$. Las resoluciones de la Suprema Corte de Justicia sólo podrán declarar la invalidez de las normas impugnadas, si fueren aprobadas por cuando menos ocho votos. Si no se aprobaran por la mayoría indicada, el Tribunal Pleno desestimará la acción ejercitada y ordenará el archivo del asunto. Si con posterioridad a la entrada en vigor de la declaratoria se aplicará la norma general declarada inválida, el afectado podrá denunciar dicho acto de conformidad con el procedimiento previsto para tal efecto en la Ley de Amparo, Reglamentaria de los artículos $103^{\circ}$ y $107^{\circ}$ de la Constitución Política de los Estados Unidos Mexicanos.

${ }^{12}$ Artículo $1^{\circ}$ de los derechos humanos; artículo $2^{\circ}$ composición pluricultural de la nación. Artículo $3^{\circ}$ derecho a la educación; artículo $4^{\circ}$ igualdad ante la ley, elección del número de hijos así como su espaciamiento; artículo $16^{\circ}$ nadie podrá ser molestado en sus pertenencias; artículo $24^{\circ}$ libertad de convicciones éticas, con- 
el que en dicha porción normativa se redefinió el concepto de persona para efectos locales, ya que a partir de la fecundación nos encontraríamos frente a una persona, ${ }^{13}$ de lo anterior se desprendería que el no nacido sería sujeto de derechos. Para el grupo de legisladores que promovían la presente acción, esta noción del concepto de persona contravendría lo establecido por derecho civil, dentro del cual se dota de derechos a las personas a partir del momento de su nacimiento. Entre los conceptos de invalidez también se mencionaba el que con ella se impondría una creencia, la cual traería como resultado la violación del principio del Estado laico, el derecho a la libertad de creencias, así como el carácter multicultural del Estado y la restricción de los derechos de las mujeres.

En cuanto a violaciones procesales durante el proceso legislativo, si bien los legisladores promoventes no alegaron ninguna, el municipio de San Luis Potosí manifestó no haberse pronunciado a favor ni en contra del proyecto, ante lo que la SCJN determinó que no hubo violaciones al proceso ya que se tenían los votos necesarios para continuar con el proyecto de reforma.

La referida acción de inconstitucionalidad, al ser estudiada por la SCJN, fue registrada bajo el número 62/2009 y se encontró al igual que la acción predecesora (11/2009) a cargo del Ministro José Fernando Franco González Salas. El Ministro Franco propuso fuera declarado inválido el primer párrafo del artículo $16^{\circ}$ de la constitución de San Luis Potosí, primeramente en cuanto a considerar el derecho a la vida como fundamento de todos los derechos de los seres humanos, así como al establecer que la vida iniciaba desde el momento de la concepción.

Si bien meses atrás la SCJN había resuelto la acción de inconstitucionalidad 11/2009 y ambas se encontraron a cargo del ministro Franco Salas, no se trataba de asuntos idénticos ya que los artículos constitucionales en pugna, si bien protegían el derecho a la vida desde la concepción, las legislaturas locales optaron por hacerlo de maneras distintas.

A diferencia del artículo $7^{\circ}$ de la Constitución de Baja California, el artículo $16^{\circ}$ de la Constitución de San Luis Potosí optó por establecer que dicha protección era brindada desde la concepción en razón de que en dicho momento comenzaba la vida, la cual es fundamento de todos los Derechos Humanos.

Dentro de la discusión de este asunto, los ministros se pronunciaron con los mismos argumentos presentados durante la audiencia relativa a la acción de inconstitucionalidad 11/2009. A pesar de no coincidir nuevamente con todos los puntos del proyecto formulado por el ministro Franco a través del cual se declararía la invalidez del artículo $16^{\circ}$ de la Constitución local de San Luis Potosí, este proyecto obtuvo un total de 7 votos a favor, lo anterior por parte de los ministros Cossío Díaz, Franco González Salas, Zaldívar Lelo de Larrea, Aguilar Morales, Valls Hernández, Sánchez Cordero y el entonces presidente Juan Silva Meza. En contra del proyecto se pronunciaron los ministros Aguirre Anguiano, Luna Ramos, Pardo Rebolledo y Ortiz Mayagoitia. Nuevamente hizo falta solo un voto para declarar dicho artículo como inconstitucional de conformidad a lo establecido en el artículo $72^{\circ}$ de la Ley Reglamentaria de las fracciones I Y II del artículo $105^{\circ}$ de la Constitución Política

ciencia y religión; artículo $40^{\circ}$ forma de gobierno; artículo $41^{\circ}$ poderes de la unión; artículo $128^{\circ}$ protección de la constitución y leyes; artículo $130^{\circ}$ Estado laico; artículo $133^{\circ}$ los tratados forman parte de la Ley Suprema de la Unión.

${ }^{13}$ En relación a esto cabe mencionar que según criterios científicos referidos por la $\mathrm{CrIDH}$ en la sentencia Artavia Murillo vs. Costa Rica, la fecundación tiene lugar en la unión del espermatozoide y el óvulo. 
de los Estados Unidos Mexicanos, lo que dio como resultado el desestimar la Acción de Inconstitucionalidad 62/ 2009 así como su archivo.

\section{ESTÁNDARES INTERNACIONALES SOBRE LA PROTECCIÓN DEL DERECHO A LA VIDA DESDE EL MOMENTO DE LA CONCEPCIÓN}

El derecho a la vida se encuentra ampliamente reconocido en diversos instrumentos internacionales, tanto universales como regionales, dedicados a la protección de los derechos humanos. Dentro del Sistema Interamericano de protección a los Derechos Humanos (en adelante, SIDH) el art. 4.1 de la Convención Americana sobre Derechos Humanos (en adelante, $\mathrm{CADH}$ ) establece que: Toda persona tiene derecho a que se respete su vida. Este derecho estará protegido por la ley y, en general, a partir del momento de la concepción. Nadie puede ser privado de la vida arbitrariamente.

La Corte Interamericana de Derechos Humanos (en adelante, CrIDH), había tomado decisiones respecto al derecho a la vida, relacionadas con garantías, como las derivadas de hechos relacionados con ejecuciones extrajudiciales, por ejemplo, Caso de los Niños de la Calle (Villagrán Morales y otros)14; Caso Myrna Mack Chang ${ }^{15}$ y Caso Escué Zapata ${ }^{16}$; las masacres, por ejemplo, Caso Barrios Altos; ${ }^{17}$ Caso del Penal Miguel Castro Castro;18 y Caso de la Masacre de la Rochela, ${ }^{19}$ la aplicación inadecuada o injustificada de la pena de muerte, por ejemplo, Caso Hilaire, Constantine y Benjamin y otros; ${ }^{20}$ así como el Caso Fermín Ramírez ${ }^{21}$ y Caso Boyce, ${ }^{22}$ entre otros. Sin embargo, en ninguna de estas decisiones se había pronunciado respecto al momento del inicio ni la protección de la vida en supuestos diferentes a los mencionados, hasta que fue emitida la Sentencia del Caso Artavia Murillo en el año 2012.

En esta sentencia, la CrIDH estableció que una interpretación en sentido literal del artículo 4.1 de la CADH de la expresión en general permite inferir la existencia de excepciones a la regla, las cuales pueden ser identificadas a través de otros métodos interpretativos como la interpretación sistemática, evolutiva, más favorable y teleológica. ${ }^{23}$

En su interpretación sistemática, la CrIDH encontró que el embrión no puede ser considerado persona en los términos del artículo 4 de la $\mathrm{CADH}$, ni en los trabajos preparatorios de esta convención. En su interpretación evolutiva la CrIDH observó que las tendencias

${ }^{14}$ CrIDH. Caso de los "Niños de la Calle" (Villagrán Morales y otros) Vs. Guatemala. Fondo. Sentencia de 19 de noviembre de 1999. Serie C No. 63.

${ }^{15}$ CrIDH. Caso Myrna Mack Chang vs. Guatemala. Fondo, Reparaciones y Costas. Sentencia de 25 de noviembre de 2003. Serie C No. 101.

${ }^{16} \mathrm{CrIDH}$. Caso Escué Zapata Vs. Colombia. Fondo, Reparaciones y Costas. Sentencia de 4 de julio de 2007. Serie C No. 165

${ }^{17}$ CrIDH. Caso Barrios Altos Vs. Perú. Fondo. Sentencia de 14 de marzo de 2001. Serie C No. 75.

${ }^{18}$ CrIDH. Caso del Penal Miguel Castro Castro Vs. Perú. Fondo, Reparaciones y Costas. Sentencia de 25 de noviembre de 2006. Serie C No. 160

${ }^{19}$ CrIDH. Caso de la Masacre de la Rochela Vs. Colombia. Fondo, Reparaciones y Costas. Sentencia de 11 de de mayo de 2007. Serie C No. 163.

${ }^{20}$ CrIDH. Caso Hilaire, Constantine y Benjamin y otros Vs. Trinidad y Tobago. Fondo, Reparaciones y Costas. Sentencia de 21 de junio de 2002. Serie C No. 94.

${ }^{21}$ CrIDH. Caso Fermín Ramírez Vs. Guatemala. Fondo, Reparaciones y Costas. Sentencia de 20 de junio de 2005. Serie C No. 126.

${ }^{22}$ CrIDH. Caso Boyce y otros. Vs. Barbados. Excepción Preliminar, Fondo, Reparaciones y Costas. Sentencia de 20 de noviembre de 2007. Serie C No. 169.

${ }^{23}$ CrIDH. Caso Artavia Murillo y otros ("Fertilización in vitro") vs Costa Rica. Excepciones Preliminares, Fondo, Reparaciones y Costas, Sentencia de 28 de noviembre de 2012, Serie C No. 257, párr. 191, 245, 81. 
relativas al derecho internacional no llevan a la conclusión de que el embrión sea tratado igual que una persona o que tenga derecho a la vida. Así mismo la CrIDH consideró que el objeto y fin de la expresión "en general" del artículo 4.1 de la CADH implica el que no pueda alegarse la protección absoluta del embrión por encima de otros derechos. ${ }^{24}$

El mismo artículo fue estudiado años atrás por la Comisión Interamericana de Derechos Humanos (en adelante, CIDH) en el caso Baby Boyvs. Estados Unidos, donde la cuestión del aborto fue abordada en dos aspectos principales en la elaboración de la CADH respecto al derecho a la vida, que destaca en primer lugar, que la frase en general dejó abierta la posibilidad de que los estados Partes en una futura convención pudieran incluir los más diversos casos de aborto, el segundo, se centra en que hay que tener en cuenta las circunstancias bajo las cuales se practicó el aborto en cada caso para evaluar si su práctica viola el artículo 4 o no. ${ }^{25}$

Si bien la CrIDH ha señalado que el derecho a la vida es un derecho humano fundamental, cuyo goce pleno es prerrequisito para el disfrute de todos los demás derechos humanos, ${ }^{26}$ esto no supone una mayor jerarquía y la inexistencia de la necesidad de que este derecho sea ponderado con otros, por lo tanto, este derecho es susceptible de ceder frente a otros derechos.

En la ya referida sentencia del caso Artavia Murillo vs. Costa Rica, sentando un importante precedente, la $\mathrm{CrIDH}$ ha establecido que el objeto directo de protección de la vida prenatal es la mujer embarazada ${ }^{27}$ y por lo tanto deben ser tomados en cuenta sus derechos, protegiendo sus intereses primero.

Al respecto cabe recordar el criterio de la SCJN en la resolución de la Contradicción de Tesis 293/2011, donde se estableció que la jurisprudencia de la CrIDH constituye una extensión de la $\mathrm{CADH}$ y que como intérprete último de la $\mathrm{CADH}$, todos los criterios que emita la $\mathrm{CrIDH}$ en sus resoluciones, incluyendo aquellas donde el Estado Mexicano no haya sido parte, son vinculantes para todos los órganos jurisdiccionales de México. ${ }^{28}$

En cuanto al Sistema Universal de protección a los Derechos Humanos, ni en su Observación General No. 6 (derecho a la vida), ${ }^{29}$ ni en su Observación General No. 17 (Derechos del niño), ${ }^{30}$ el Comité de Derechos Humanos de la Organización de las Naciones Unidas (en adelante, $\mathrm{CDH}$ ) se ha pronunciado sobre el derecho a la vida del no nacido. Por el contrario, en sus observaciones finales a los informes de los distintos estados, el Comité de Derechos Humanos ha señalado que se viola el derecho a la vida de la madre cuando las leyes que restringen el acceso al aborto obligan a la mujer a recurrir al aborto inseguro, exponiéndola a

\footnotetext{
${ }^{24}$ Íbidem, párr. 264.

${ }^{25}$ CIDH. Resolución 23/81, caso 2141, Estados Unidos, 6 de marzo de 1981, Párrafo 14.

${ }^{26}$ CrIDH. Caso de los "Niños de la Calle" (Villagrán Morales y otros) Vs Guatemala. Sentencia de 19 de noviembre de 1999. Serie C No. 63, párr. 144, y Caso Comunidad indígena Xákmok Kásek Vs. Paraguay. Fondo, Reparaciones y Costas. Sentencia de 24 de agosto de 2010. Serie C No. 214, párr. 186.

27 CrIDH. Caso Artavia Murillo y otros ("Fecundación in vitro") Vs. Costa Rica, Excepciones Preliminares, Fondo, Reparaciones y Costas, sentencia de 28 de noviembre de 2012, párrafo 222.

${ }^{28}$ Contradicción de Tesis 293/2011, Gaceta del Semanario Judicial de la Federación, Décima Época, Libro 5, Abril de 2014, Tomo I, p. 96.

${ }^{29}$ Comité de Derechos Humanos, Observación General No. 6, Derecho a la vida (artículo 6), U.N. Doc. HRI/ GEN/1/Rev.7 at 143 (1982).

30 Comité de Derechos Humanos, Observación General No. 17, Derechos del niño (artículo 24), U.N. Doc. HRI/GEN/1/Rev.7 at 165 (1989).
} 
morir.$^{31}$ Estas decisiones permiten afirmar que del Pacto Internacional de Derechos Civiles y Políticos (PIDCP) tampoco se deriva una protección absoluta de la vida prenatal.

Por otro lado, los informes del Comité para la Eliminación de la Discriminación contra la Mujer (en adelante, Comité CEDAW) han coincidido en que los principios de igualdad y no discriminación deben privilegiar los derechos de la mujer embarazada por encima del interés de protección del no nacido. ${ }^{32}$

En el caso particular de nuestro país, las Observaciones Finales del Comité CEDAW dirigidas a México en 2012, el Comité externó que: Le preocupa que las enmiendas introducidas en las constituciones locales que protegen la vida desde el momento de la concepción hayan puesto en peligro el disfrute por la mujer de su salud y derechos sexuales y reproductivos, aun cuando esas enmiendas no hayan modificado los motivos jurídicos ya establecidos para practicar un aborto.

$\mathrm{Al}$ respecto, el Comité pidió a México:

a) Armonice las leyes federales y estatales relativas al aborto a fin de eliminar los obstáculos que enfrentan las mujeres que deseen interrumpir un embarazo de forma legal y amplíe también el acceso al aborto legal teniendo en cuenta la reforma constitucional en materia de derechos humanos y la recomendación general núm. 24 (1999) del Comité;

b) Informe a los proveedores de servicios médicos y trabajadores sociales que las enmiendas constitucionales locales no han derogado los motivos para interrumpir un embarazo de forma legal y les comunique también las responsabilidades que les incumben;

c) Se asegure de que en todos los estados las mujeres que tengan motivos legales que justifiquen la interrupción de un embarazo tengan acceso a servicios médicos seguros, y vele por la debida aplicación de la Norma Oficial Mexicana NOM-046-SSA2-2005, en particular el acceso de las

\footnotetext{
${ }^{31}$ Comité de Derechos Humanos, Argentina, $\$ 14$, UN Doc. CCPR/CO/70/arg (200o); Bolivia, § 22, UN Doc. CCPR/C/79/Ad.74 (1997); Costa Rica, \$11, UN Doc. CCPR/C/79/Ad.107 (1999); Chile, \$15, UN Doc. CCPR/C/79/ Add.104 (1999); El Salvador, \$14, UN Doc. CCPR/CO/78/SLV (2003); Ecuador, \$11, UN Doc. CCPR/C/79/ Add.92 (1998); Gambia, $\$ 17$, UN Doc. CCPR/CO/75/GMB (2004); Guatemala, $\$ 19$, UN Doc. CCPR/CO/72/ GTM (2001); Honduras, $\$ 8$, UN Doc. CCPR/C/HND/CO/1 (2006); Kenia, $\$ 14$, UN Doc. CCPR/CO/83/KEN (2005); Kuwait, $\$ \$$ 9, CCPR/CO/69/KWT (2000); Lesotho, $\$ 11$, UN Doc. CCPR/C/79/Add.106 (1999); Islas Mauricio, $\$$ 9, UN Doc. CCPR/CO/83/MUS (2005); Marruecos, $\$ 29$, UN Doc. CCPR/CO/82/MAR (2004); Paraguay, $\$ 10$, UN Doc. CCPR/C/PRY/CO/2 (2006); Perú, $\$ 15$, UN Doc. CCPR/C/79/Ad.72 (1996); Perú, $\$$ 20, UN Doc. CCPR/CO/70/PER (2000); Polonia, \$8, UN Doc. CCPR/CO/82/POL (2004); República de Tanzania, \$15, UN Doc. CCPR/C/79/Ad.97 (1998); Trinidad y Tobago, \$18, UN Doc. CCPR/CO/70/TTO (2000); Venezuela, $\$$ 19, UN Doc. CCPR/CO/71/VEN (2001), y Vietnam, $\$ 15$, UN Doc. CCPR/CO/75/VNM (2002). Caso K.L. vs. Perú, CDH, Com. No 1153/2003, Doc. ONU CCPR/C/85/D/1153/2003 (2005) y Caso L.M.R. vs. Argentina, CDH, Com. No 1608/2007, Doc. ONU CCPR/C/101/D/1608/2007 (2011).

${ }^{32}$ ONU, Comité para la eliminación de la discriminación contra la mujer (CEDAW), Caso L.C. vs. Perú, Com. No 22/2009, (18 de junio de 2009), disponible en: http://www.ohchr.org/Documents/HRBodies/CEDAW/ Jurisprudence/CEDAW-C-50-D-22- 2009_sp.pdf; CrIDH. Caso Artavia Murillo y otros ("Fecundación In vitro") Vs. Costa Rica, excepciones Preliminares, Fondo, Reparaciones y Costas. Sentencia de 28 de noviembre de 2012, párrafo 227.
} 
mujeres que han sido violadas a anticonceptivos de emergencia, al aborto y a tratamiento para la prevención de enfermedades de transmisión sexual y el VIH/SIDA. ${ }^{33}$

Puede apreciarse que los estándares internacionales en la materia, se orientan hacia la protección de los derechos de la mujer embarazada por encima de aquellos del no nacido. Además, en ninguno de los instrumentos internacionales en materia de derechos humanos, ni en las interpretaciones por parte de los órganos de vigilancia de los mismos, se ha reconocido que el no nacido sea titular de derechos, incluyendo el derecho a la vida.

\section{CONCLUSIONES}

A partir de lo mencionado anteriormente, podemos concluir que las reformas a las constituciones de diversos estados que surgen con la finalidad de blindarlas ante la posible despenalización del aborto, así como la interpretación que se realice de estas, pueden considerarse preocupantes por representar una posible limitante a los derechos de las mujeres. Sin embargo, los estándares interamericanos de protección a los derechos humanos parecen indicarnos que no necesariamente son excluyentes la protección de la vida prenatal con la protección de los derechos de la mujer embarazada, sino todo lo contrario

El criterio de la CrIDH en el que interpreta la disposición convencional que hace referencia al deber de los estados de proteger la vida prenatal, considerado por la propia SCJN como una norma vinculante para México, establece que esta protección debe realizarse a través de la mujer embarazada, concediéndole atenciones antes y durante un lapso razonable después del parto.

En este orden de ideas, la constitucionalización de la protección de la vida prenatal por parte de las entidades federativas, en ningún caso debería utilizarse como justificación para la criminalización de las mujeres y, por el contrario, debería ir de la mano de un fortalecimiento del marco normativo e institucional de protección a los derechos de las mujeres en estado de gravidez, quienes se encuentran en una doble situación de vulnerabilidad, que se traduce en una mayor obligación del Estado de proteger sus intereses.

Resulta lamentable que las y los ministros de la SCJN hayan desaprovechado dos oportunidades importantes para pronunciarse en torno a la interrupción legal del embarazo, al desestimar y archivar las acciones de inconstitucionalidad 11/2009 y 62/2009 como resultado a la ausencia de un voto a favor del proyecto que declararía la inconstitucionalidad de dichas reformas.

No obstante lo anterior, tal como se mencionó desde el inicio de este artículo, dentro de las distintas legislaturas locales se siguen presentando iniciativas en el sentido de proteger constitucionalmente la vida prenatal, lo que implica la posibilidad de que a través de una futura acción de inconstitucionalidad, la SCJN se pronuncie en un sentido más progresista y acorde a los estándares internacionales en la materia.

\footnotetext{
33 Comité CEDAW, Observaciones finales del Comité para la Eliminación de la Discriminación contra la Mujer: México, 520 período de sesiones (2012), párr. 32, [CEDAW/C/MEX/CO/7-8], http://www.un.org/ga/ search/view_doc.asp?symbol=CEDAW/C/MEX/CO/7-8\&referer=/english/\&Lang=S
} 
V. FUENTES

Comisión Interamericana de Derechos Humanos. Resolución 23/81, caso 2141, Estados Unidos, 6 de marzo de 1981, Párrafo 14.

Comité de Derechos Humanos de la Organización de las Naciones Unidas, Observación General No. 6, Derecho a la vida (artículo 6), U.N. Doc. HRI/GEN/1/Rev.7 at 143 (1982).

Observación General No. 17, Derechos del niño (artículo 24), U.N. Doc. HRI/GEN/1/Rev.7 at 165 (1989).

, Observaciones finales a Perú, UN Doc. CCPR/C/79/Ad.72 (1996).

, Observaciones finales a Bolivia, UN Doc. CCPR/C/79/Ad.74 (1997).

, Observaciones finales a Ecuador, UN Doc. CCPR/C/79/Add.92 (1998).

Ad.97 (1998).

Observaciones finales a República de Tanzania, UN Doc. CCPR/C/79/

, Observaciones finales a Costa Rica, UN Doc. CCPR/C/79/Ad.107 (1999). , Observaciones finales a Chile, UN Doc. CCPR/C/79/Add.104 (1999).

, Observaciones finales a Lesotho, UN Doc. CCPR/C/79/Add.106 (1999).

, Observaciones finales a Kuwait, CCPR/CO/69/KWT (2000).

, Observaciones finales a Argentina, UN Doc. CCPR/CO/70/arg (2000).

, Observaciones finales a Perú, UN Doc. CCPR/CO/70/PER (2000).

(2000).

, Observaciones finales a Trinidad y Tobago, UN Doc. CCPR/CO/70/TTO

, Observaciones finales a Venezuela, UN Doc. CCPR/CO/71/VEN (2001).

, Observaciones finales a Guatemala, UN Doc. CCPR/CO/72/GTM (2001). , Observaciones finales a Vietnam, UN Doc. CCPR/CO/75/VNM (2002).

, Observaciones finales a El Salvador, UN Doc. CCPR/CO/78/SLV (2003). , Observaciones finales a Marruecos, UN Doc. CCPR/CO/82/MAR (2004). , Observaciones finales a Gambia, UN Doc. CCPR/CO/75/GMB (2004). , Observaciones finales a Polonia, UN Doc. CCPR/CO/82/POL (2004). , Observaciones finales a Kenia, UN Doc. CCPR/CO/83/KEN (2005). , Observaciones finales a Islas Mauricio, UN Doc. CCPR/CO/83/MUS (2005). 
, Caso K.L. vs. Perú, CDH, Com. No 1153/2003, Doc. ONU CCPR/ $\mathrm{C} / 85 / \mathrm{D} / 1153 / 2003$ (2005).

, Observaciones finales a Honduras, UN Doc. CCPR/C/HND/CO/1

(2006).

, Observaciones finales a Paraguay, UN Doc. CCPR/C/PRY/CO/2 (2006).

, Caso L.M.R. vs. Argentina, CDH, Com. No 1608/2007, Doc. ONU CCPR/C/101/D/1608/2007 (2011).

Comité para la Eliminación de la Discriminación contra la Mujer (CEDAW) de la Organización de las Naciones Unidas, Caso L.C. vs. Perú, Com. No 22/2009, (18 de junio de 2009).

, Observaciones finales del Comité para la Eliminación de la Discriminación contra la Mujer: México, 520 período de sesiones (2012), párr. 32, UN Doc. $\mathrm{CEDAW} / \mathrm{C} / \mathrm{MEX} / \mathrm{CO} / 7-8$.

Corte Interamericana de Derechos Humanos. Caso de los "Niños de la Calle" (Villagrán Morales y otros) Vs. Guatemala. Fondo. Sentencia de 19 de noviembre de 1999. Serie C No. 63 .

Serie C No. 75.

Caso Barrios Altos Vs. Perú. Fondo. Sentencia de 14 de marzo de 2001.

, Caso Hilaire, Constantine y Benjamin y otros Vs. Trinidad y Tobago. Fondo, Reparaciones y Costas. Sentencia de 21 de junio de 2002. Serie C No. 94.

Caso Myrna Mack Chang vs. Guatemala. Fondo, Reparaciones y Costas. Sentencia de 25 de noviembre de 2003. Serie C No. 101.

Caso Fermín Ramírez Vs. Guatemala. Fondo, Reparaciones y Costas. Sentencia de 20 de junio de 2005. Serie C No. 126.

Caso del Penal Miguel Castro Castro Vs. Perú. Fondo, Reparaciones y Costas. Sentencia de 25 de noviembre de 2006. Serie C No. 160.

Caso de la Masacre de la Rochela Vs. Colombia. Fondo, Reparaciones y Costas. Sentencia de 11 de de mayo de 2007. Serie C No. 163.

, Caso Escué Zapata Vs. Colombia. Fondo, Reparaciones y Costas. Sentencia de 4 de julio de 2007. Serie C No. 165.

Caso Boyce y otros. Vs. Barbados. Excepción Preliminar, Fondo, Reparaciones y Costas. Sentencia de 20 de noviembre de 2007. Serie C No. 169.

, Caso Comunidad indígena Xákmok Kásek Vs. Paraguay. Fondo, Reparaciones y Costas. Sentencia de 24 de agosto de 2010. Serie C No. 214. 
Caso Artavia Murillo y otros (“Fertilización in vitro") vs Costa Rica. Excepciones Preliminares, Fondo, Reparaciones y Costas, Sentencia de 28 de noviembre de 2012, Serie C No. 257.

FERRAJOLI, Luigi, Derechos y garantías. La ley del más débil. Traducción de Perfecto Andrés Ibáñez y Andrea Greppi, 7a. ed., Madrid, Trotta, 2010, 175 pp.

"La cuestión del embrión entre derecho y moral", Jueces para la democracia. Información y debate, núm. 44, Madrid, 2002, pp. 3-12.

KANT, I., La metafísica de las costumbres, trad. A. Cortina Orts, Tecnos, Madrid, 1989.

Suprema Corte de Justicia de la Nación. Contradicción de Tesis 293/2011, Gaceta del Semanario Judicial de la Federación, Décima Época, Libro 5, Abril de 2014, Tomo I, p. 96. Acción de inconstitucionalidad 146/2007 y su acumulada 147/2007. Registro Núm. 21469; Novena Época; pleno; Semanario Judicial de la Federación y su Gaceta Tomo XXIX, Marzo de 2009, página 1421.

Acción de inconstitucionalidad 11/2009. Registro Núm. 23348; Novena Época; Pleno; Semanario Judicial de la Federación y su Gaceta Libro IV, Enero de 2012 , Tomo 1, página 615

Acción de inconstitucionalidad 62/2009. Registro Núm. 23349 Novena Época; Pleno. Semanario Judicial de la Federación y su Gaceta, Libro IV, Enero de 2012, Tomo 1, página 789. 


\section{ANEXO: ESTADOS DE LA REPÚBLICA QUE HAN INCORPORADO A SUS TEXTOS CONSTITUCIONALES LA PROTECCIÓN DE LA VIDA PRENATAL ${ }^{34}$}

Se enlista en orden cronológico conforme la fecha de publicación en los diarios oficiales o gacetas estatales.

\begin{tabular}{|c|c|c|c|}
\hline Año & Estado & Artículo reformado & Información adicional \\
\hline 1994 & Chihuahua & $\begin{array}{l}\text { Artículo } 5^{\circ} \text {.- Todo ser humano tiene } \\
\text { derecho a la protección jurídica de su } \\
\text { vida, desde el momento mismo de la } \\
\text { concepción. En el Estado de Chihuahua } \\
\text { no podrá establecerse la pena de muer- } \\
\text { te. }\end{array}$ & $\begin{array}{l}\text { Al ser reformado en el } \\
\text { año } 1994 \text {, no se con- } \\
\text { sidera parte de dicho } \\
\text { movimiento. } \\
\text { Publicado en el P.O.E. el } \\
1^{\circ} \text { de octubre de } 1994 .\end{array}$ \\
\hline 2008 & Morelos & $\begin{array}{l}\text { Artículo } 2^{\circ} . \text { - En el Estado de Morelos } \\
\text { se reconoce que todo ser humano tie- } \\
\text { ne derecho a la protección jurídica de } \\
\text { su vida, desde el momento mismo de la } \\
\text { concepción, y asegura a todos sus habi- } \\
\text { tantes, el goce de los Derechos Huma- } \\
\text { nos, contenidas en la Constitución Po- } \\
\text { lítica de los Estados Unidos Mexicanos } \\
\text { y en la presente Constitución y, acorde } \\
\text { con su tradición libertaria, declara de } \\
\text { interés público la aplicación de los artí- } \\
\text { culos } 27 \text { y } 123 \text {, de la Constitución Fun- } \\
\text { damental de la República y su legisla- } \\
\text { ción derivada. }\end{array}$ & $\begin{array}{l}\text { Reforma aprobada el } 11 \\
\text { de Noviembre de } 2008 \text {. } \\
\text { Publicada el } 11 \text { Diciem- } \\
\text { bre de } 2008 \text { en el P.O.E. } \\
\text { de Morelos. }\end{array}$ \\
\hline
\end{tabular}

\footnotetext{
${ }^{34}$ Elaborada a partir de la consulta de los textos constitucionales de las entidades federativas vigentes al 22 de febrero de 2016.
} 


\begin{tabular}{|c|c|c|c|}
\hline 2008 & $\begin{array}{l}\text { Baja } \\
\text { California }\end{array}$ & $\begin{array}{l}\text { Artículo } 7^{\circ} \text {.- El Estado de Baja Califor- } \\
\text { nia acata plenamente y asegura a todos } \\
\text { sus habitantes los derechos humanos } \\
\text { reconocidos en la Constitución Políti- } \\
\text { ca de los Estados Unidos Mexicanos, y } \\
\text { en los Tratados Internacionales de los } \\
\text { que el Estado Mexicano sea parte, así } \\
\text { como las garantías para su protección, } \\
\text { y los demás derechos que reconoce esta } \\
\text { Constitución, cuyo ejercicio no podrá } \\
\text { restringirse ni suspenderse, salvo en } \\
\text { los casos y bajo las condiciones que es- } \\
\text { tablece la Constitución Política de los } \\
\text { Estados Unidos Mexicanos; de igual } \\
\text { manera esta norma fundamental tutela } \\
\text { el derecho a la vida, desde el momen- } \\
\text { to en que un individuo es concebido, } \\
\text { entra bajo la protección de la Ley y se } \\
\text { le reputa como nacido para todos los } \\
\text { efectos legales correspondientes, hasta } \\
\text { su muerte natural o no inducida. }\end{array}$ & $\begin{array}{l}\text { Reforma aprobada en el } \\
\text { Congreso el } 23 \text { de octu- } \\
\text { bre de } 2008 \text {. } \\
\text { Publicada el } 26 \text { de di- } \\
\text { ciembre de } 2008 \text { en el } \\
\text { P.O.E. } \\
\text { La SCJN analizó el con- } \\
\text { tenido de dicho precep- } \\
\text { to constitucional. }\end{array}$ \\
\hline 2009 & Colima & $\begin{array}{l}\text { Artículo } 1^{\circ} . \text {-La vida es un derecho in- } \\
\text { herente a toda persona. El Estado pro- } \\
\text { tegerá y garantizará este derecho desde } \\
\text { el momento de la concepción. }\end{array}$ & $\begin{array}{l}\text { Reforma aprobada por } \\
\text { el Congreso el } 17 \text { de } \\
\text { febrero de } 2009 \text { y cóm- } \\
\text { puto de votos del Cons- } \\
\text { tituyente Permanente el } \\
20 \text { de marzo de } 2009 \text {, } \\
\text { aprobada por afirmati- } \\
\text { va ficta. } \\
\text { Publicada el } 21 \text { de Mar- } \\
\text { zo de } 2009 \text { en el P.O.E. }\end{array}$ \\
\hline
\end{tabular}




\begin{tabular}{|c|c|c|c|}
\hline 2009 & Sonora & $\begin{array}{l}\text { Artículo } 1^{\circ} .-[\ldots] \text { El Estado de Sonora } \\
\text { tutela el derecho a la vida, al sustentar } \\
\text { que desde el momento de la fecun- } \\
\text { dación de un individuo, entra bajo la } \\
\text { protección de la ley y se le reputa como } \\
\text { nacido para todos los efectos legales co- } \\
\text { rrespondientes, hasta su muerte natu- } \\
\text { ral. Se exceptúa de este reconocimiento, } \\
\text { el aborto causado por culpa de la mujer } \\
\text { embarazada o cuando el embarazo sea } \\
\text { resultado de una violación o cuando, de } \\
\text { no provocarse el aborto, la mujer emba- } \\
\text { razada corra peligro de muerte, a juicio } \\
\text { del médico que la asista, oyendo éste el } \\
\text { dictamen de otro médico, siempre que } \\
\text { esto fuere posible y no sea peligrosa la } \\
\text { demora, }\end{array}$ & $\begin{array}{l}\text { Reforma aprobada por } \\
\text { el Congreso el } 21 \text { de } \\
\text { Octubre de } 2008 \text {. Cóm- } \\
\text { puto de la votación del } \\
\text { Constituyente Perma- } \\
\text { nente el } 31 \text { de marzo de } \\
2009 \text {. } \\
\text { Publicada en el P.O.E. el } \\
6 \text { de abril de } 2009 \text {. }\end{array}$ \\
\hline 2009 & Guanajuato & $\begin{array}{l}\text { Artículo } 1^{\circ} \text {.- Para los efectos de esta } \\
\text { Constitución y de las leyes que de ella } \\
\text { emanen, persona es todo ser humano } \\
\text { desde su concepción hasta su muerte } \\
\text { natural. El Estado le garantizará el pleno } \\
\text { goce y ejercicio de todos sus derechos. } \\
\text { Párrafo reformado P.O. 26-05-2009 }\end{array}$ & $\begin{array}{l}\text { Reforma aprobada por } \\
\text { el Congreso el } 8 \text { de } \\
\text { Mayo de } 2009 \text {. } \\
\text { Publicada el } 26 \text { de Mayo } \\
\text { de } 2009 \text { en el P.O.E. del } \\
\text { Estado de Guanajuato. }\end{array}$ \\
\hline 2009 & $\begin{array}{l}\text { Quintana } \\
\text { Roo }\end{array}$ & $\begin{array}{l}\text { Artículo } 13^{\circ} . \text { - El Estado de Quintana } \\
\text { Roo reconoce, protege y garantiza el } \\
\text { derecho a la vida de todo ser humano, } \\
\text { al sustentar expresamente que desde el } \\
\text { momento de la concepción entra bajo la } \\
\text { protección de la ley y se le reputa como } \\
\text { sujeto de derechos para todos los efec- } \\
\text { tos legales correspondientes, hasta su } \\
\text { muerte. Salvo las excepciones que esta- } \\
\text { blezca la ley. }\end{array}$ & $\begin{array}{l}\text { Reforma aprobada por } \\
\text { el Congreso el } 21 \text { de } \\
\text { Abril de } 2009 \text { Cómputo } \\
\text { realizado el } 12 \text { de Mayo } \\
\text { de } 2009 \\
\text { Publicada en el P.O.E. el } \\
15 \text { Mayo } 2009 \text {. }\end{array}$ \\
\hline 2009 & Durango & $\begin{array}{l}\text { Artículo } 3^{\circ} \text {.- El Estado de Durango re- } \\
\text { conoce, protege y garantiza el derecho a } \\
\text { la vida de todo ser humano, al sustentar } \\
\text { expresamente que desde el momento de } \\
\text { la fecundación entra bajo la protección } \\
\text { de la ley y se le reputa como nacido para } \\
\text { todos los efectos legales correspondien- } \\
\text { tes, hasta su muerte natural, salvo las } \\
\text { excepciones que establezca la ley. }\end{array}$ & $\begin{array}{l}\text { Reforma aprobada por } \\
\text { el Congreso el } 07 \text { de } \\
\text { Abril de 2009, Cóm- } \\
\text { puto realizado el } 19 \text { de } \\
\text { Mayo de } 2009 \text {. } \\
\text { Publicada en } 31 \text { de } \\
\text { Mayo de } 2009 \text { en el } \\
\text { P.O.E. }\end{array}$ \\
\hline
\end{tabular}




\begin{tabular}{|c|c|c|c|}
\hline 2009 & Puebla & $\begin{array}{l}\text { Artículo } 26^{\circ} \text {. } \\
\text { IV.- La vida humana debe ser protegi- } \\
\text { da desde el momento de la concepción } \\
\text { hasta su muerte natural, salvo los casos } \\
\text { previstos en las leyes; }\end{array}$ & $\begin{array}{l}\text { Reforma aprobada en el } \\
\text { Congreso el } 12 \text { de Mar- } \\
\text { zo de } 2009 \text {. Cómputo } \\
\text { de la votación del Cons- } \\
\text { tituyente Permanente } \\
15 \text { de Mayo de } 2009 . \\
\text { Publicada en el P.O.E. el } \\
3 \text { de Junio de } 2009 .\end{array}$ \\
\hline 2009 & Nayarit & $\begin{array}{l}\text { Artículo } 7^{\circ} \text {. } \\
\text { I.- Se reconoce, protege y garantiza el } \\
\text { derecho a la vida de todo ser humano } \\
\text { desde el momento de la fecundación } \\
\text { natural o artificial y se le reputa como } \\
\text { nacido para todos los efectos legales } \\
\text { correspondientes, hasta su muerte na- } \\
\text { tural. }\end{array}$ & $\begin{array}{l}\text { Reforma aprobada en el } \\
\text { Congreso el } 17 \text { de abril } \\
\text { de } 2009 \text {. Cómputo rea- } \\
\text { lizado el } 28 \text { de Mayo de } \\
2009 \text {. } \\
\text { Publicación en el } \\
\text { P.O.E.de Nayarit el } 6 \text { de } \\
\text { Junio de 2009. }\end{array}$ \\
\hline 2009 & Jalisco & $\begin{array}{l}\text { Artículo } 4^{\circ} \text {.- Asimismo, el Estado de } \\
\text { Jalisco reconoce, protege y garantiza el } \\
\text { derecho a la vida de todo ser humano, } \\
\text { al sustentar expresamente que desde el } \\
\text { momento de la fecundación entra bajo } \\
\text { la protección de la ley y se le reputa } \\
\text { como nacido para todos los efectos le- } \\
\text { gales correspondientes, hasta su muerte } \\
\text { natural. }\end{array}$ & $\begin{array}{l}\text { Reforma aprobada en el } \\
\text { Congreso el } 26 \text { de mar- } \\
\text { zo de } 2009 . \\
\text { Publicada el } 2 \text { de Julio } \\
\text { de } 2009 \text { en el P.O.E. de } \\
\text { Jalisco. }\end{array}$ \\
\hline 2009 & Yucatán & $\begin{array}{l}\text { Artículo } 1^{\circ} \text {.- El Estado de Yucatán re- } \\
\text { conoce, protege y garantiza el derecho a } \\
\text { la vida de todo ser humano, al sustentar } \\
\text { expresamente que desde el momento de } \\
\text { la fecundación entra bajo la protección } \\
\text { de la ley y se le reputa como nacido para } \\
\text { todos los efectos legales correspondien- } \\
\text { tes, hasta su muerte natural, sin perjui- } \\
\text { cio de las excluyentes de responsabi- } \\
\text { lidad previstas en el Código Penal del } \\
\text { Estado de Yucatán. }\end{array}$ & $\begin{array}{l}\text { Reforma aprobada por } \\
\text { el Congreso local e } 15 \\
\text { de julio de } 2009 \\
\text { Publicada en el P.O.E. el } \\
07 \text { de agosto de } 2009 \text {. }\end{array}$ \\
\hline
\end{tabular}




\begin{tabular}{|c|c|c|c|}
\hline 2009 & $\begin{array}{l}\text { San Luis } \\
\text { Potosí }\end{array}$ & $\begin{array}{l}\text { Artículo } 16^{\circ} \text {.- El Estado de San Luis } \\
\text { Potosí reconoce la vida humana como } \\
\text { fundamento de todos los derechos de } \\
\text { los seres humanos, por lo que la respeta } \\
\text { y protege desde el momento de su inicio } \\
\text { en la concepción. Queda prohibida la } \\
\text { pena de muerte, la cual no podrá apli- } \\
\text { carse en ningún caso. No es punible la } \\
\text { muerte dada al producto de la concep- } \\
\text { ción, cuando sea consecuencia de una } \\
\text { acción culposa de la mujer; el embarazo } \\
\text { sea resultado de una violación o de una } \\
\text { inseminación indebida; o de no provo- } \\
\text { carse el aborto la mujer corra peligro de } \\
\text { muerte }\end{array}$ & $\begin{array}{l}\text { Reforma aprobada en el } \\
\text { Congreso el } 21 \text { de mayo } \\
\text { de } 2009 \text { Cómputo reali- } \\
\text { zado el } 31 \text { de agosto de } \\
2009 \\
\text { San Luis Potosí. } \\
\text { Publicada en el P.O.E. } \\
\text { el } 03 \text { de septiembre de } \\
2009 \\
\text { La SCJN analizó el con- } \\
\text { tenido de dicho precep- } \\
\text { to constitucional. }\end{array}$ \\
\hline 2009 & Oaxaca & $\begin{array}{l}\text { Artículo } 12^{\circ} \text {.- }^{-} \text {En el Estado de Oaxa- } \\
\text { ca se protege y garantiza el derecho a } \\
\text { la vida. Todo ser humano desde el mo- } \\
\text { mento de la fecundación entra bajo la } \\
\text { protección de la ley se le reputa como } \\
\text { nacido para todos los efectos legales } \\
\text { hasta su muerte natural. }\end{array}$ & $\begin{array}{l}\text { Reforma aprobada en el } \\
\text { Congreso el } 09 \text { de sep- } \\
\text { tiembre } 2009 \\
\text { Publicada en el P.O.E. } \\
\text { el } 11 \text { de septiembre de } \\
2009 \text {. }\end{array}$ \\
\hline 2009 & Querétaro & $\begin{array}{l}\text { Artículo } 2^{\circ} \text {.- El Estado respeta, recono- } \\
\text { ce, protege y garantiza el derecho a la } \\
\text { vida de todo ser humano, desde el mo- } \\
\text { mento de la fecundación, como un bien } \\
\text { jurídico tutelado y se le reputa como } \\
\text { nacido para todos los efectos legales } \\
\text { correspondientes, hasta la muerte. Esta } \\
\text { disposición no deroga las excusas abso- } \\
\text { lutorias ya contempladas en la legisla- } \\
\text { ción penal. }\end{array}$ & $\begin{array}{l}\text { Reforma aprobada en } \\
\text { el Congreso } 01 \text { de sep- } \\
\text { tiembre de } 2009 \text { Cóm- } \\
\text { puto realizado el } 17 \text { de } \\
\text { septiembre de } 2009 \text {. } \\
\text { Publicada en el P.O.E. } \\
\text { el } 18 \text { de septiembre de } \\
2009 \text {. }\end{array}$ \\
\hline 2010 & Chiapas & $\begin{array}{l}\text { artículo } 4^{\circ} .-[\ldots] \text { El Estado reconoce, } \\
\text { protege y tutela, el derecho a la vida que } \\
\text { todo ser humano tiene. Desde el mo- } \\
\text { mento de la concepción, entra bajo la } \\
\text { protección de la Ley y se le reputa como } \\
\text { nacido para todos los efectos legales co- } \\
\text { rrespondientes, hasta su muerte natu- } \\
\text { ral, salvo las excepciones que establezca } \\
\text { la legislación penal. }\end{array}$ & $\begin{array}{l}\text { Reforma aprobada en el } \\
\text { Congreso el } 18 \text { de Di- } \\
\text { ciembre de } 2009 \text {. } \\
\text { Publicada el } 20 \text { de ene- } \\
\text { ro de } 2010 \text { en el P.O.E. }\end{array}$ \\
\hline
\end{tabular}




\begin{tabular}{|c|c|c|c|}
\hline 2010 & Tamaulipas & $\begin{array}{l}\text { Artículo } 16^{\circ} \text {.- Son habitantes del Estado } \\
\text { todas las personas que residen en su te- } \\
\text { rritorio, sea cual fuere su estado y condi- } \\
\text { ción. El pueblo de Tamaulipas establece } \\
\text { que el respeto a la vida, la dignidad de la } \\
\text { persona, la libertad, la igualdad y la jus- } \\
\text { ticia constituyen la base y el objeto de } \\
\text { las instituciones públicas y sociales. En } \\
\text { consecuencia, el Estado de Tamaulipas } \\
\text { reconoce, protege y garantiza el dere- } \\
\text { cho a la vida de todo ser humano desde } \\
\text { el momento de la fecundación hasta su } \\
\text { muerte natural; esta disposición no de- } \\
\text { roga las excusas absolutorias ya previs- } \\
\text { tas en la legislación penal. }\end{array}$ & $\begin{array}{l}\text { Reforma aprobada por } \\
\text { el Congreso el } 15 \text { de di- } \\
\text { ciembre de } 2010 \text {. Publi- } \\
\text { cada en el P.O.E. el } 23 \\
\text { de diciembre de } 2010 \text {. }\end{array}$ \\
\hline 2016 & Veracruz & $\begin{array}{l}\text { Artículo } 4^{\circ} \text { - }^{-} \text {El Estado garantizará el } \\
\text { derecho a la Vida del ser humanos, des- } \\
\text { de el momento de la concepción hasta } \\
\text { la muerte natural, como valor primor- } \\
\text { dial que sustenta el ejercicio de los de- } \\
\text { más derechos; salvo las excepciones } \\
\text { previstas en las leyes. }\end{array}$ & $\begin{array}{l}\text { Aún no es publicada en } \\
\text { la Gaceta oficial. }\end{array}$ \\
\hline
\end{tabular}

